\title{
Synthesis of Cholic Acid-Peptide Conjugates With A Negatively Charged Ester Linkage for Oral Delivery
}

Hengguang $\mathrm{Li}^{1 *}$, Haijing Song ${ }^{2}$, Svein $\mathrm{Oie}^{2}$ and $\mathrm{D}^{\prime}$ Robert $\mathrm{Lu}^{3}$

${ }^{1}$ Department of Chemistry and Physics, Fayetteville State University, Fayetteville, NC, USA

${ }^{2}$ Metabolic Center, Duke University, Durham, NC, USA

${ }^{3}$ College of Pharmacy, University of Georgia, Athens, GA, USA

\begin{abstract}
The progress in oral absorption of protein and peptide drugs has been hampered by the difficulty in transporting larger molecules across the gastrointestinal membrane. We are reporting here a study of the design and synthesis of cholic acid-peptide conjugates for peptide drug delivery through gastrointestinal track mediated by bile acid transporter. As principal samples, three small cholic acid-peptide conjugates containing a biodegradable ester bond via threonine linker have been synthesized. In order to introduce ester bond between cholic acid and peptides, conventional solid phase synthesis is not practicable, thus solution phase was employed. The threonine moiety was chosen to introduce a hydroxyl group, on which an ester bond can be formed with different peptides. The threonine moiety also provides the necessary negative charge adjacent to the C24 position as required for transport recognizing by the bile acid transporter in the ilue epicell. The synthetic process was based on DCC chemistry. By using catalytic amounts of $\mathrm{N}$-hydroxysuccinimide the procedure for amide coupling was simplified and shortened while maintaining high efficiency. Esterification using ethyl acetate in the presence of triethylamine selectively introduced an ester bond at the C27 position giving higher yield with no protection on other three hydroxyls. The work also demonstrated that in solution phase synthesis of these peptide conjugates fluoride ion $\left(F^{-}\right)$was more efficient than piperidine to cleave Fmoc from the amino group.
\end{abstract}

Cell culture experiment showed the efficiencies of transporting of the conjugates and the dissociation of the conjugates detected by HPLC, suggesting that the cholic acid conjugates linked by degradable ester bond can be used as bigger molecule drugs delivering template. Further study would be designed by using more different linkers that would be also biodegradable bonds, such as thioester and so forth.

Keywords: Cholic acid; Peptides; Conjugation; Drug delivery

Abbreviations: DCM: Dichloromethane; DMAP: 4-Dimethylaminopyridine; TEA: Triethylamine; DCC: 1,3 Dicycloheylcarbodiimide; THF: Tetrahydrofuran; DMF: N, N-Dimethylformamide; FMOC: 9-Fluorenylmethoxycarbonyl; CA: Cholic Acid; DCM: Dichloromethane; CDI: 1, 1'-Carboxyldiimidazole; TFA: Trifluoroacetic Acid.

\section{Introduction}

Advances in biotechnology have provided a wide range of therapeutically active and commercially available biologic large molecules as protein and peptide drugs [1-3]. However, oral administration of these drugs has been highly limited due to the stability and the difficulties to cross the gastrointestinal membrane. Significant research attempts have been made in recent years to utilize carrier-mediated transport systems for enhancement in the oral bioavailability. Among various intestinal transporters, the intestinal bile acid transporter has a good potential because of its higher capacity and low structural selectivity [4-7]. The transport system facilitates the daily absorption of $10-20 \mathrm{~g}$ bile salts at a more than $95 \%$ efficiency rate. The system also tolerates significant chemical modifications at the C3 and C24 positions of the sterol nucleus. Thus, the intestinal bile acid transporter has been specifically investigated for its ability to increase the oral absorption of cholic acid conjugates of proteins and small peptides through the carrier-mediated transport mechanism [4-7]. The fact that the bile acid transporter tolerates the chemical modifications of cholic acid provides a solid rationale for the development of a cholic acid-peptide conjugate for enhanced oral absorption [8-10].

Earlier work from our laboratory and others have found that conjugates of peptides with cholic acid interact with and are transported by the human bile acid transporter $[11,12]$. The interaction was largely dependent on the ionization and the location of several ionizable group(s) on the conjugates. Compounds with a single negative charge at the 26-28 positions in Scheme 1 demonstrated maximum interaction with the transporter while the addition of a second negative charge in the vicinity caused a reduction in activity [13,14]. A single positive charge resulted in loss of activity. Neutral compounds showed a reduction in the affinity. Experiments in our laboratory and others

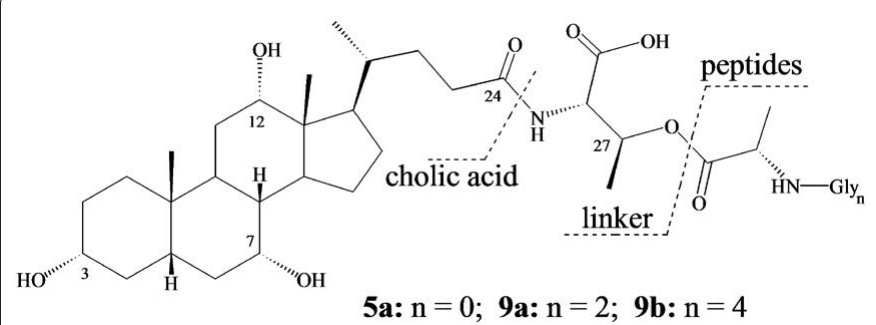

Scheme 1: Structure of cholic acid-peptide conjugates with a threonine ester linker.

*Corresponding author: Hengguang Li, Department of Chemistry and Physics Fayetteville State University, Fayetteville, NC 28301, USA, Tel: 410-900-3013 (or) 910-672-2651; E-mail: hli@uncfsu.edu

Received January 22, 2017; Accepted February 02, 2017; Published February 06, 2017

Citation: Li H, Song H, Oie S, Lu RD (2017) Synthesis of Cholic Acid-Peptide Conjugates With A Negatively Charged Ester Linkage for Oral Delivery. Med Chem (Los Angeles) 7: 769-776. doi: 10.4172/2161-0444.1000428

Copyright: $\odot 2017$ Hengguang Li, et al. This is an open-access article distributed under the terms of the Creative Commons Attribution License, which permits unrestricted use, distribution, and reproduction in any medium, provided the original author and source are credited. 
the oral absorption in proper animal model was Caco-2 Cell line. The CaCo-2 cell line was originally isolated from a primary colonic tumor. Upon reaching confluence, the cells express characteristics of enterocytic differentiation. CaCo-2 cells express retinoic acid binding protein I and retinol binding protein II and are keratin positive.

\section{Experimental Procedure}

Melting points were determined on a MelTemp-II melting point apparatus and are reported as uncorrected values. NMR data were recorded on a Bruker 400 AMX spectrometer and the chemical shifts $(\delta)$ are reported in parts per million (ppm). Coupling constants $(\mathrm{J})$ are

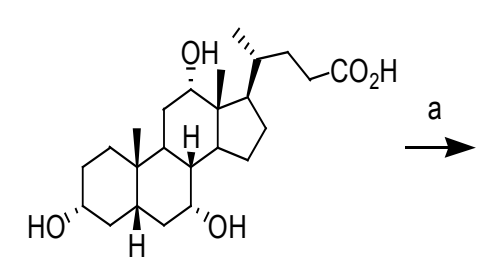

1<smiles>CCC1CCC2C1C(O)CC1C2C(O)CC2C(O)CCCC21C</smiles>

2

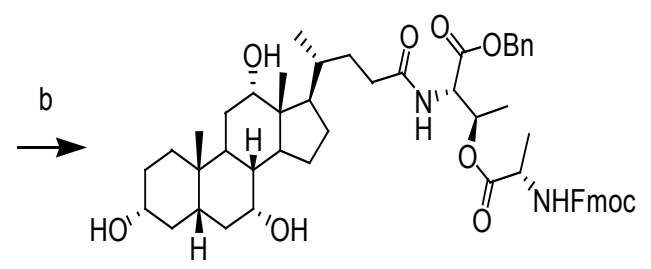

3<smiles>CC(=O)OC(=O)C=C=C(C)CBr</smiles>

Scheme 2: Reagents and condition: (a) (1) H-Thr-Obzl-1/2 oxalate, NaHCO3, DCM, room temperature (r.t.); (2) N- Hydroxysuccinimide, DCC, DCM, r.t.; (b) FmocAla-OH, TEA, DCC, ethyl acetate, $0^{\circ} \mathrm{C}$; or $1,1^{\prime}$-carboxyldiimidazole (CDI), 4-dimethylaminopyridine (DMAP), DCM, $0^{\circ} \mathrm{C}$.
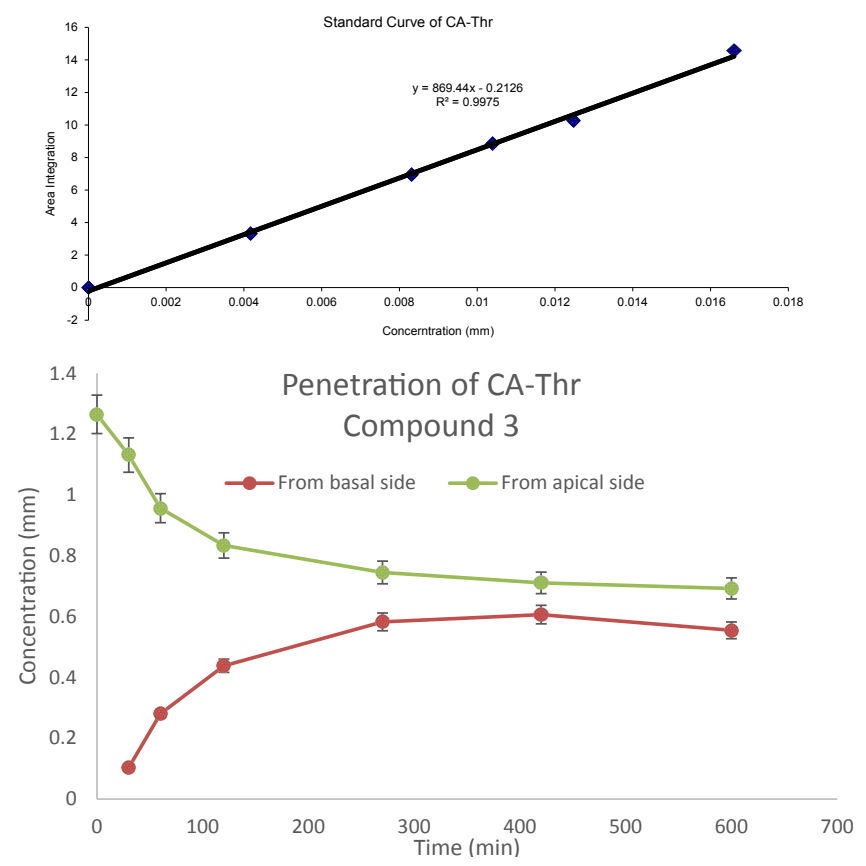

Figure 1: Penetration of CA-Thr Compound 3.

also showed no differences in affinity to the transporter between $\mathrm{D}$ and $\mathrm{L}$ amino acid conjugates [15-17]. These results indicate that cholic acid-peptide conjugates with appropriate chemical arrangements can be effectively transported via the bile acid carrier-mediated transport mechanism. However, as a prodrug, the conjugate must also meet the requirement that it be able to release the therapeutic parent peptide unit after crossing the gastrointestinal membrane. This report details the construction of an ester linkage between cholic acid and peptide using threonine as the linker, and the synthesis of three target compounds, cholyl-[L-Thr-(D-Ala-amino acid or peptide) ester] amides (5a), (9a), (9b) (Scheme 1). The general structure of this type of compounds can be divided into three parts (Figure 1): the cholic acid (CA), the threonine linker connecting to the $\mathrm{C} 24$ position of $\mathrm{CA}$ and the peptides attached to the linker with an ester bond. Our experiments show that with proper modifications in general procedure of peptide chemistry it is feasible to synthesize such a group of cholic acid-peptide conjugates. The biological potentials of these conjugates, however, need to be further verified involving the in vitro cell culture studies and in vivo animal studies. Specifically, the future studies will include the examination of the chemical stability and biodegradation of these conjugates in biological environments.

The transport profiles through cell culture membrane system and 
reported in Hertz. The abbreviations used are as follows: s (singlet), d (doublet), $\mathrm{t}$ (triplet), q (quartet), $\mathrm{m}$ (multiplet), dd (double doublet), pt (pseudo triplet), brs (broad singlet). Mass spectra were either recorded on a Micro-mass Autospec high-resolution (FAB) mass spectrometer or obtained from the Department of Chemistry Mass Spectrometry facility at the University of Georgia. Standard workup procedure after the reactions, where specified, was to wash the reaction mixture with equal volume of saturated sodium bicarbonate solution and brine with subsequent drying of the organic layer (sodium sulfate or magnesium sulfate). All of the chemicals were purchased from Aldrich Chemical Co., ACROS ORGANICS, Fisher Scientific, Sigma Chemicals, or Lancaster Synthesis. Chromatography refers to flash chromatography conducted on Kieselgel 60 230-400 mesh (E. Merck, Darmstadt) using the indicated solvents. Thin-layer chromatography (TLC) was performed on precoated Merck silica gel $60 \mathrm{~F}_{254}$ plates.

The Caco-2 Cell line, Dulbecco's modified Eagle's medium (DMEM), fetal bovine serum (FBS), modified Hanks' balanced salt solution (HBSS) and non-essential amino acid (NEAA) were from American Type Culture Collection (ATCC). Insert transwell ${ }^{\mathrm{TM}}$ clusters coated with Rat tail collagen ( $24.5 \mathrm{~mm}$ diameter, 3.0 um pore size) were obtained from VWR Scientific Products.

\section{Cholyl-L-(OBzl)Thr Amide (2)}

$\mathrm{NaHCO}_{3}(1 \mathrm{~N})$ was added to a solution of $\mathrm{H}-\mathrm{Thr}-\mathrm{OBzl}-$ oxalate $(0.8 \mathrm{~g}, 3.0 \mathrm{mmol})$ in water $(50 \mathrm{ml})$ to adjust the $\mathrm{pH}$ to 7.5 at $0^{\circ} \mathrm{C}$, and extracted with DCM $(3 \times 30 \mathrm{ml})$. The organic layers were combined and dried over anhydrous $\mathrm{Na}_{2} \mathrm{SO}_{4}$. Cholic acid (1.2 g, $\left.3.0 \mathrm{mmol}\right)$ was added to the solution followed by $\mathrm{N}$-hydroxysuccinimide $(24 \mathrm{mg}, 0.2$ mmol) under vigorous stirring. A solution of DCC $(0.7 \mathrm{~g}, 3.1 \mathrm{mmol})$ in DCM was added slowly to the mixture and allowed to react at room temperature for five hours. The reaction mixture was filtered, and the filtrate was washed with water, saturated $\mathrm{NaHCO}_{3}$ and brine, respectively. The organic layers were combined, dried over anhydrous $\mathrm{Na}_{2} \mathrm{SO}_{4}$, concentrated via vacuo and purified via silica gel flash column chromatography (ethyl acetate/methanol 0:100-1:99) to obtain a white solid of 2 ( $1.6 \mathrm{~g}, 88 \%$; $\left.\mathrm{mp} 98-100^{\circ} \mathrm{C}\right)$.

${ }^{1} \mathrm{HNMR}\left(400 \mathrm{MHz}, \mathrm{CDCl}_{3}\right) 0.67\left(\mathrm{~s}, 3 \mathrm{H}, \mathrm{CH}_{3}\right), 0.88\left(\mathrm{~s}, 3 \mathrm{H}, \mathrm{CH}_{3}\right)$, $0.98(\mathrm{~d}, \mathrm{~J}=6.8 \mathrm{~Hz}, 3 \mathrm{H}, \mathrm{CH} 3), 1.00\left(\mathrm{~d}, \mathrm{~J}=2.0 \mathrm{~Hz}, 3 \mathrm{H}, \mathrm{CH}_{3}\right), 1.12-2.38$ (m, 24H, cholyl), 3.48 (s, 2H, CH), 3.45 (brs, $1 \mathrm{H}, \mathrm{CH}), 3.84$ (b, 1H, CH), 3.97(s, 1H, CH), $4.36(\mathrm{~m}, 1 \mathrm{H}, \mathrm{CH}), 4.64(\mathrm{~m}, 1 \mathrm{H}, \mathrm{CH}), 5.18(\mathrm{pt}, 2 \mathrm{H}, \mathrm{J}=$ $\left.12.4,2.0 \mathrm{~Hz}, \mathrm{CH}_{2}\right), 5.30(\mathrm{~s}, 1 \mathrm{H}, \mathrm{CH}), 6.75(\mathrm{~d}, 1 \mathrm{H}, \mathrm{J}=7.2 \mathrm{~Hz}, \mathrm{CH}), 7.30$ (m, $5 \mathrm{H} . \mathrm{C}_{6} \mathrm{H}_{5}$ ).

${ }^{13} \mathrm{C}$ NMR: $174.8,172.1,141.0,128.9,128.8,127.5,127.4,127.4,82.1$, $72.1,71.9,69.0,67.4,62.9,50.6,50.0,44.8,42.8,41.8,37.6,37.2,37.2$, 35.2, 33.1, 32.2, 31.4, 30.5, 29.0, 29.3, 28.8, 25.3, 17.9, 17.3, 12.5, 6.5 .

HRMS (FAB) for $\mathrm{C}_{35} \mathrm{H}_{53} \mathrm{NO}_{7}: \mathrm{m} / \mathrm{z}$ Found 599.3895, Calcd.599.3872.

MS: $\mathrm{m} / \mathrm{z} 622(\mathrm{M}+\mathrm{Na})^{+}, 600(\mathrm{M}+1)^{+}, 582\left(\mathrm{M}-\mathrm{H}_{2} \mathrm{O}\right)^{+}, 564\left(\mathrm{M}-2 \mathrm{H}_{2} \mathrm{O}\right)^{+}$, $546\left(\mathrm{M}-3 \mathrm{H}_{2} \mathrm{O}\right)^{+}$.

\section{Cholyl-[L-(OBzl)Thr-D-Fmoc-Ala Ester] Amide (3a)}

Method 1: To a mixture of Fmoc-Ala-OH (1.2 g, $3.8 \mathrm{mmol})$ and the prepared Cholyl-L-(OBzl)Thr Amide $2(2.2 \mathrm{~g}, 3.8 \mathrm{mmol})$ in ethyl acetate $(30 \mathrm{ml})$ was added a solution of DCC $(0.78 \mathrm{~g}, 3.8 \mathrm{mmol})$ in ethyl acetate $(15 \mathrm{ml})$ at $0^{\circ} \mathrm{C}$, and followed by addition of triethylamine (TEA) $(0.4 \mathrm{~g}, 3.8 \mathrm{mmol})$ and stirred for 3 hours at room temperature. When TLC indicated that the reaction was completed, the mixture was filtered, and the filtrate was washed with water, saturated $\mathrm{NaHCO}_{3}$ and brine, respectively. The organic layers were combined and dried over anhydrous $\mathrm{Na}_{2} \mathrm{SO}_{4}$, concentrated via vacuo and purified via silica gel flash column chromatography (ethyl acetate/ hexanes $0: 100$ to $80: 20$ ) to obtain syrup of 3 (2.78 g, 82\%).

Method 2: To a solution of Fmoc-Ala-OH (1.2 g, $3.8 \mathrm{mmol})$ in DCM $(20 \mathrm{ml})$ was added 1, 1'-carboxyldiimidazole (CDI) (0.64 g, 4.0 mmol) while stirring under an atmosphere of $\mathrm{N}_{2}$ at $0^{\circ} \mathrm{C}$. The mixture was stirred for one half hour, added to a solution of $2(2.2 \mathrm{~g}, 3.8 \mathrm{mmol})$ in DCM $(20 \mathrm{ml})$, heated to room temperature and allowed to react for two days. The crude product was treated in the same manner as described in method 1 to obtain the solid amide of $3(0.88 \mathrm{~g}, 26 \% ; \mathrm{mp}$ $\left.101-103^{\circ} \mathrm{C}\right)$

${ }^{1} \mathrm{HNMR}\left(400 \mathrm{MHz}, \mathrm{CDCl}_{3}\right) 0.67\left(\mathrm{~s}, 3 \mathrm{H}, \mathrm{CH}_{3}\right), 0.88\left(\mathrm{~s}, 3 \mathrm{H}, \mathrm{CH}_{3}\right)$, $1.06\left(\mathrm{~d}, \mathrm{~J}=2.0 \mathrm{~Hz}, 3 \mathrm{H}, \mathrm{CH}_{3}\right), 1.09\left(\mathrm{~d}, \mathrm{~J}=9.3 \mathrm{~Hz}, 3 \mathrm{H}, \mathrm{CH}_{3}\right), 1.12-2.38(\mathrm{~m}$, $24 \mathrm{H}$, cholyl), $2.03\left(\mathrm{~s}, 3 \mathrm{H}, \mathrm{CH}_{3}\right), 3.43(\mathrm{~b}, 1 \mathrm{H}, \mathrm{CH}), 3.81(\mathrm{~s}, 1 \mathrm{H}, \mathrm{CH}), 3.94$ $(\mathrm{s}, 1 \mathrm{H}, \mathrm{CH}), 4.22(\mathrm{dd}, 1 \mathrm{H}, \mathrm{J}=7.6,6.8 \mathrm{~Hz}, \mathrm{CH}), 4.52(\mathrm{~d}, 1 \mathrm{H}, \mathrm{J}=5.6 \mathrm{~Hz}$, $\mathrm{CH}), 4.88(\mathrm{~d}, 1 \mathrm{H}, \mathrm{J}=9.2 \mathrm{~Hz}, \mathrm{CH}), 5.13(\mathrm{~m}, 2 \mathrm{H}, \mathrm{CH}), 5.26(\mathrm{~m}, 1 \mathrm{H}, \mathrm{CH})$, $5.46(\mathrm{~m}, 1 \mathrm{H}, \mathrm{CH}), 6.51(\mathrm{~d}, 1 \mathrm{H}, \mathrm{J}=9.2 \mathrm{~Hz}, \mathrm{NH}), 7.20\left(\mathrm{~m}, 5 \mathrm{H}, 2 \mathrm{H}, \mathrm{C}_{6} \mathrm{H}_{5}\right.$ ArH), $7.38(\mathrm{~m}, 2 \mathrm{H}, \mathrm{ArH}), 7.58$ (d, 2H, J = 7.2Hz, ArH), $7.76(\mathrm{~d}, 2 \mathrm{H}, \mathrm{J}$ $=7.3 \mathrm{~Hz}, \mathrm{ArH})$.

${ }^{13}$ CNMR: $174.8,172.1,172.1,157.6,142.0,142.0,141.0,136.6$, $136.6,128.9,128.9,128.8,128.8,127.9,127.9,127.4,127.3,127.3,126.6$, 82.1, 73.0, 72.1, 71.9, 71.2, 69.0, 59.7, 53.6, 50.6, 50.0, 44.9, 42.8, 41.8, $37.9,37.7,37.2,37.2,35.2,33.1,32.2,31.4,30.5,29.3,29.0,28.8,25.3$, $17.9,16.7,14.1,12.5,6.5$.

HRMS (FAB) for $\mathrm{C}_{54} \mathrm{H}_{68} \mathrm{~N}_{2} \mathrm{O}_{10}: \mathrm{m} / \mathrm{z}$ Found 892.4916, Calcd. 892.4937.

\section{MS: $\mathrm{m} / \mathrm{z} 893(\mathrm{M}+1)^{+}$}

\section{Cholyl-(L-Thr-D-FmocAla Ester) Amide (4a)}

Method 1: To a solution of 3 ( $0.5 \mathrm{~g}, 0.6 \mathrm{mmol})$ in methanol (15 $\mathrm{ml}), 10 \%$ palladium on activated carbon $(5 \mathrm{mg})$ was added. The flask was placed in a vacuum to remove air and subsequently flushed with dry $\mathrm{N}_{2}$. The reaction flask was filled with $\mathrm{H}_{2}$ in the presence of a few drops of $0.1 \mathrm{~N} \mathrm{HCl}$ and stirred at room temperature for 24 hours. The reaction mixture was filtered. The filtrate was concentrated via vacuo and purified through silica gel column chromatography (ethyl acetate/ methanol 100:0 to 80:10) to obtain amide of $4(0.47 \mathrm{~g}, 97 \%)$ as a white solid.

Method 2: To a solution of 3 (0.5 g, $0.6 \mathrm{mmol})$ in DCM (35 ml) $99 \%$ pure hydrazine monohydrate $(30 \mathrm{~g}, 0.6 \mathrm{mmol})$ was added and vigorously stirred at room temperature overnight. After TLC indicated the deprotection was completed, the mixture was diluted with ethyl acetate $(15 \mathrm{ml})$. The reaction mixture was washed with water, $0.1 \mathrm{~N} \mathrm{HCl}$ and brine respectively. The organic layers were dried over anhydrous $\mathrm{NaSO}_{4}$, concentrated and isolated via silica gel column chromatography (ethyl acetate/methanol 100:0 to 80:10) to obtain the amide of $4(0.40 \mathrm{~g}$, $82 \%$; $\mathrm{mp} 105^{\circ}-107^{\circ} \mathrm{C}$ ) as a white solid.

${ }^{1} \mathrm{HNMR}\left(400 \mathrm{MHz}, \mathrm{CDCl}_{3}\right) 0.66\left(\mathrm{~s}, 3 \mathrm{H}, \mathrm{CH}_{3}\right), 0.86\left(\mathrm{~s}, 3 \mathrm{H}, \mathrm{CH}_{3}\right)$, $0.97\left(\mathrm{~d}, \mathrm{~J}=5.6 \mathrm{~Hz}, 3 \mathrm{H}, \mathrm{CH}_{3}\right), 1.09\left(\mathrm{~d}, \mathrm{~J}=7.6 \mathrm{~Hz}, 3 \mathrm{H}, \mathrm{CH}_{3}\right), 1.26(\mathrm{t}, 2 \mathrm{H}, \mathrm{J}$ $\left.=7.2 \mathrm{~Hz}, \mathrm{CH}_{2}\right), 1.12-2.38(\mathrm{~m}, 24 \mathrm{H}$, cholyl $), 2.04\left(\mathrm{~s}, 3 \mathrm{H}, \mathrm{CH}_{3}\right), 3.44(\mathrm{brs}$, $1 \mathrm{H}, \mathrm{NH}), 3.83(\mathrm{~s}, 1 \mathrm{H}, \mathrm{CH}), 3.96(\mathrm{~s}, 1 \mathrm{H}, \mathrm{OH}), 4.12(\mathrm{q}, 1 \mathrm{H}, \mathrm{J}=7.2 \mathrm{~Hz}$, $\mathrm{CH}), 4.33$ (dd, $1 \mathrm{H}, \mathrm{J}=7.6,6.8 \mathrm{~Hz}, \mathrm{CH}), 4.43$ (brs, $1 \mathrm{H}, \mathrm{OH}), 5.69$ (brs, $1 \mathrm{H}, \mathrm{OH}), 6.02$ (brs, 1H, NH), 7.23 (m, 2H, ArH), 7.34 (m, 2H, ArH), $7.57(\mathrm{~m}, 2 \mathrm{H}, \mathrm{ArH}), 7.70(\mathrm{~d}, 2 \mathrm{H}, \mathrm{J}=6.4 \mathrm{~Hz}, \mathrm{ArH})$.

${ }^{13} \mathrm{CNMR}: 177.1,174.8,172.1,157.6,142.0,142.0,136.6,136.6$, $128.9,128.9,127.9,127.9,126.6,82.1,73.0,71.9,70.8,69.0,61.8,53.6$, 50.6, 50.0, 44.9, 42.8, 41.8, 37.9, 37.7, 37.2, 37.2, 35.2, 33.1, 32.2, 31.4, $30.5,29.3,29.0,28.8,25.3,17.9,16.7,14.1,12.5,6.5$. 
Citation: Li H, Song H, Oie S, Lu RD (2017) Synthesis of Cholic Acid-Peptide Conjugates With A Negatively Charged Ester Linkage for Oral Delivery. Med Chem (Los Angeles) 7: 769-776. doi: 10.4172/2161-0444.1000428 824.4432 .

HRMS (FAB) for $\mathrm{C}_{46} \mathrm{H}_{62} \mathrm{~N}_{2} \mathrm{NaO}_{10}: \mathrm{m} / \mathrm{z}$ Found 824.4474, Calcd.

MS: $\mathrm{m} / \mathrm{z} 847(\mathrm{M}+1+2 \mathrm{Na})^{+}, 825(\mathrm{M}+1+\mathrm{Na})^{+}$.

\section{Cholyl-(L-Thr-D-Ala Ester) Amide (5a)}

To a solution of $4(235 \mathrm{mg}, 0.3 \mathrm{mmol})$ in DMF $(10 \mathrm{ml})$ and THF $(5 \mathrm{ml})$, anhydrous $\mathrm{KF}(1.2 \mathrm{~g}, 2.1 \mathrm{mmol})$ was added and stirred at room temperature for 15 minutes. TEA $(1.5 \mathrm{ml})$ was slowly added to the mixture, and after a 5-hour reaction interval celite $(1.0 \mathrm{~g})$ was added. The mixture was filtered and the resulting cake was washed with methanol. The filtrates were combined; the combined filtrate was condensed to $5 \mathrm{ml}$ under reduced pressure and the residue was diluted with ethyl acetate $(40 \mathrm{ml})$ under shaking. The precipitate was separated by centrifugation at $3500 \mathrm{r} / \mathrm{min}$, and the collected precipitate was washed twice with ethyl acetate. The solid product was dried in a vacuum overnight to obtain the white solid of 5 (182 $\mathrm{mg}, 88 \%$; $\mathrm{mp}$ $\left.105^{\circ}-108^{\circ} \mathrm{C}\right)$.

${ }^{1} \mathrm{HNMR}\left(400 \mathrm{MHz}, \mathrm{CD}_{3} \mathrm{OD}\right) 0.75\left(\mathrm{~d}, \mathrm{~J}=3.58 \mathrm{~Hz}, 3 \mathrm{H}, \mathrm{CH}_{3}\right), 0.95(\mathrm{~d}$, $\left.\mathrm{J}=3.76 \mathrm{~Hz}, 3 \mathrm{H}, \mathrm{CH}_{3}\right), 1.02\left(\mathrm{~d}, \mathrm{~J}=6.8 \mathrm{~Hz}, 3 \mathrm{H}, \mathrm{CH}_{3}\right), 1.07(\mathrm{~d}, \mathrm{~J}=5.6 \mathrm{~Hz}$ $\left.3 \mathrm{H}, \mathrm{CH}_{3}\right), 1.10\left(\mathrm{~d}, \mathrm{~J}=9.6 \mathrm{~Hz}, 3 \mathrm{H}, \mathrm{CH}_{3}\right), 1.26\left(\mathrm{t}, 2 \mathrm{H}, \mathrm{J}=7.2 \mathrm{~Hz}, \mathrm{CH}_{2}\right)$, 1.12-2.50 (m, $24 \mathrm{H}$, cholyl), 3.44 (brs, $1 \mathrm{H}, \mathrm{NH}), 3.84(\mathrm{~s}, 1 \mathrm{H}, \mathrm{OH}), 4.01$ $(\mathrm{d}, 1 \mathrm{H}, \mathrm{J}=3.20 \mathrm{~Hz}, \mathrm{CH}), 4.33(\mathrm{dd}, 1 \mathrm{H}, \mathrm{J}=7.6,6.8 \mathrm{~Hz}, \mathrm{CH}), 4.43$ (brs, $1 \mathrm{H}$, $\mathrm{OH}), 5.50(\mathrm{~m}, 1 \mathrm{H}, \mathrm{NH})$.

${ }^{13}$ CNMR: $177.1,174.8,172.1,82.1,71.9,70.8,69.0,61.8,55.1,50.6$, $50.0,44.9,42.8,41.7,37.8,37.2,37.2,35.2,33.1,32.2,31.4,30.5,29.3$, 29.0, 28.8, 25.3, 19.4, 17.9, 14.1, 12.5, 6.5 .

HRMS (FAB) for $\mathrm{C}_{31} \mathrm{H}_{52} \mathrm{~N}_{2} \mathrm{O}_{8}: \mathrm{m} / \mathrm{z}$ Found 580.3782, Calcd. 580.3725 .

MS: $\mathrm{m} / \mathrm{z} 602(\mathrm{M}+\mathrm{Na})^{+}, 600(\mathrm{M}-2 \mathrm{H}+\mathrm{Na})^{+}, 581(\mathrm{M}+1)^{+}, 565(\mathrm{M}-$ $\left.\mathrm{CH}_{3}\right)^{+}, 548\left(\mathrm{M}-2 \mathrm{CH}_{3}-1\right)^{+}$.

\section{Cholyl-[L-(OBzl)Thr-D-Ala Ester] Amide (6)}

Method 1: To a solution of $3(0.5 \mathrm{~g}, 0.6 \mathrm{mmol})$ in DMF $(5 \mathrm{ml}) \mathrm{KF}$ $(0.1 \mathrm{~g}, 2 \mathrm{mmol})$ was added under constant stirring at room temperature, followed by the addition of TEA $(1.2 \mathrm{ml})$ within 1 min under an atmosphere of $\mathrm{N}_{2}$. The reaction was allowed to continue for 48 hours under constant stirring. Celite $(0.5 \mathrm{~g})$ was added, and the mixture was filtered. The filtrate was concentrated via vacuo and purified through silica gel column chromatography (ethyl acetate/methanol 100: 0 to $80: 20)$, to obtain a solid of $6(0.35 \mathrm{~g}, 87 \%)$.

Method 2: To a solution of $3(0.5 \mathrm{~g}, 0.6 \mathrm{mmol})$ in DCM $(20 \mathrm{ml})$ and piperidine $(8 \mathrm{mg}, 0.1 \mathrm{mmol})$ was slowly added at room temperature under vigorous stirring. After an overnight reaction, the solvent was removed via vacuo and the residue was purified through silica gel column chromatography to obtain a solid of $6(0.17 \mathrm{~g}, 31 \%$; $\mathrm{mp} 109$ $\left.112^{\circ} \mathrm{C}\right)$.

${ }^{1} \mathrm{HNMR}\left(400 \mathrm{MHz}, \mathrm{CDCl}_{3}\right) 0.67\left(\mathrm{~s}, 3 \mathrm{H}, \mathrm{CH}_{3}\right), 0.88$ (s, 3H, $\left.\mathrm{CH}_{3}\right)$, $1.00\left(\mathrm{~d}, \mathrm{~J}=2.0 \mathrm{~Hz}, 3 \mathrm{H}, \mathrm{CH}_{3}\right), 1.10\left(\mathrm{~d}, \mathrm{~J}=9.5 \mathrm{~Hz}, 3 \mathrm{H}, \mathrm{CH}_{3}\right), 1.27(\mathrm{~d}, \mathrm{~J}=$ $\left.4.6 \mathrm{~Hz}, 3 \mathrm{H}, \mathrm{CH}_{3}\right), 1.12-2.38\left(\mathrm{~m}, 24 \mathrm{H}\right.$, cholyl), $3.20\left(\mathrm{~b}, 2 \mathrm{H}, \mathrm{NH}_{2}\right), 3.43$ (b, $1 \mathrm{H}, \mathrm{CH}), 3.81(\mathrm{~s}, 1 \mathrm{H}, \mathrm{CH}), 3.94(\mathrm{~s}, 1 \mathrm{H}, \mathrm{CH}), 4.22(\mathrm{dd}, 1 \mathrm{H}, \mathrm{J}=7.6$, $6.8 \mathrm{~Hz}, \mathrm{CH}), 4.52(\mathrm{~d}, 1 \mathrm{H}, \mathrm{J}=5.6 \mathrm{~Hz}, \mathrm{CH}), 4.88(\mathrm{~d}, 1 \mathrm{H}, \mathrm{J}=9.2 \mathrm{~Hz}, \mathrm{CH})$, $5.13(\mathrm{~m}, 2 \mathrm{H}, \mathrm{CH}), 5.26(\mathrm{~m}, 1 \mathrm{H}, \mathrm{CH}), 5.46(\mathrm{~m}, 1 \mathrm{H}, \mathrm{CH}), 6.51(\mathrm{~d}, 1 \mathrm{H}, \mathrm{J}=$ 9.2 $\mathrm{Hz}, \mathrm{NH}), 7.28\left(\mathrm{~s}, 5 \mathrm{H}, \mathrm{C}_{6} \mathrm{H}_{5}\right)$.

${ }^{13}$ CNMR: $174.8,172.1,172.1,141.0,128.8,128.8,127.5,127.4$, $127.4,82.1,71.9,72.3,70.9,69.0,59.6,55.1,50.6,50.0,44.9,42.8,41.7$, $37.8,37.2,37.2,35.2,33.1,32.2,31.4,30.5,29.3,29.0,28.8,25.3,19.4$, $17.9,14.1,12.5,6.5$.
HRMS (FAB) for $\mathrm{C}_{38} \mathrm{H}_{58} \mathrm{~N}_{2} \mathrm{O}_{8}: \mathrm{m} / \mathrm{z}$ Found 670.4271, Calcd.670.4257.

Where MS: m/z $671(\mathrm{M}+1)^{+}$.

\section{Cholyl-[L-(OBzl)Thr-(D-Ala-BocGly) Ester] Amide (7a)}

To a solution of $6(0.5 \mathrm{~g}, 0.6 \mathrm{mmol})$ in DMF $(5 \mathrm{ml})$ and THF (20 $\mathrm{ml})$ was added Boc-Gly-OH $(0.1 \mathrm{~g}, 2 \mathrm{mmol})$ at room temperature with stirring and allowed to react for 5 minutes. N-hydroxysuccinimide (3 $\mathrm{mg}, 0.06 \mathrm{mmol})$ and TEA $(0.5 \mathrm{ml})$ was added to the solution and DCC (134 mg, $0.65 \mathrm{mmol})$ in DCM $(5 \mathrm{ml})$ was subsequently slowly added over 1 minute. The mixture was stirred for two hours and then filtered. The filtrate was concentrated in vacuum and purified via silica gel column chromatography (ethyl acetate/methanol from 100:0 to 90:10) to obtain the solid of $7 \mathrm{a}\left(0.35 \mathrm{~g}, 70 \% ; \mathrm{mp} 98-101^{\circ} \mathrm{C}\right)$.

${ }^{1} \mathrm{HNMR}\left(400 \mathrm{MHz}, \mathrm{CDCl}_{3}\right) 0.69$ (s, 3H, $\left.\mathrm{CH}_{3}\right), 0.90$ (s, 3H, $\mathrm{CH}_{3}$ ), $1.01\left(\mathrm{~d}, \mathrm{~J}=4.8 \mathrm{~Hz}, 3 \mathrm{H}, \mathrm{CH}_{3}\right), 1.10\left(\mathrm{~d}, \mathrm{~J}=9.3 \mathrm{~Hz}, 3 \mathrm{H}, \mathrm{CH}_{3}\right), 1.28(\mathrm{~d}, \mathrm{~J}=$ $\left.4.4 \mathrm{~Hz}, 3 \mathrm{H}, \mathrm{CH}_{3}\right), 1.46\left(\mathrm{~s}, 9 \mathrm{H}, \mathrm{CH}_{3}\right), 1.32-2.00(\mathrm{~m}, 26 \mathrm{H}$, cholyl), $2.35(\mathrm{~d}$, $\mathrm{J}=8.4 \mathrm{~Hz}, 1 \mathrm{H}, \mathrm{CH}), 2.22(\mathrm{~d}, \mathrm{~J}=9.6 \mathrm{~Hz}, 1 \mathrm{H}, \mathrm{CH}), 3.45$ (brs, $2 \mathrm{H}, \mathrm{NH})$, $3.68\left(\mathrm{dd}, \mathrm{J}=10.8,72.0 \mathrm{~Hz}, 2 \mathrm{H}, \mathrm{CH}_{2}\right), 3.86(\mathrm{~s}, 1 \mathrm{H}, \mathrm{CH}), 3.99(\mathrm{~s}, 1 \mathrm{H}, \mathrm{CH})$, $4.12(\mathrm{q}, 1 \mathrm{H}, \mathrm{J}=5.6 \mathrm{~Hz}, \mathrm{CH}), 4.90(\mathrm{~d}, 1 \mathrm{H}, \mathrm{J}=6.8 \mathrm{~Hz}, \mathrm{OH}), 4.97(\mathrm{brs}, 1 \mathrm{H}$, $\mathrm{CH}), 5.14\left(\mathrm{dd}, 2 \mathrm{H}, \mathrm{J}=9.6,30.8 \mathrm{~Hz}, \mathrm{CH}_{2}\right), 5.50$ (brs, $\left.1 \mathrm{H}, \mathrm{CH}\right), 6.49(\mathrm{~d}$, $1 \mathrm{H}, \mathrm{J}=7.2 \mathrm{~Hz}, \mathrm{NH}), 7.38\left(\mathrm{~s}, 5 \mathrm{H}, \mathrm{C}_{6} \mathrm{H}_{5}\right)$.

${ }^{13}$ CNMR: $174.8,172.1,172.1,171.0,157.9,141.0,128.8,128.8,127.5$, $127.4,127.4,82.1,72.3,71.9,70.9,70.7,69.0,59.6,51.9,50.6,50.0,48.7$, $44.9,42.8,41.7,37.8,37.2,37.2,35.2,33.1,32.2,31.4,30.5,29.3,29.0$, $28.8,28.7,28.7,25.3,17.9,16.7,14.1,12.5,6.5$.

HRMS (FAB) for $\mathrm{C}_{45} \mathrm{H}_{69} \mathrm{~N}_{3} \mathrm{O}_{11}$ : $\mathrm{m} / \mathrm{z}$ Found 827.4952, Calcd.827.4983.

MS: $\mathrm{m} / \mathrm{z} 828(\mathrm{M}+1)^{+}$.

\section{Cholyl-[L-(OBzl)Thr-(D-Ala-Gly-Gly-BocGly) Ester] Amide (7b)}

Compound 6 was coupled with Boc-Gly-Gly-Gly-OH, using a method similar to that described for $\mathbf{7 a}$ to obtain a white solid of $\mathbf{7 b}$ (250 mg, 72\%; mp 103-107 C).

${ }^{1} \mathrm{HNMR}\left(400 \mathrm{MHz}, \mathrm{CDCl}_{3}\right) 0.69\left(\mathrm{~s}, 3 \mathrm{H}, \mathrm{CH}_{3}\right), 0.90\left(\mathrm{~s}, 3 \mathrm{H}, \mathrm{CH}_{3}\right)$, $1.01\left(\mathrm{~d}, \mathrm{~J}=4.8 \mathrm{~Hz}, 3 \mathrm{H}, \mathrm{CH}_{3}\right), 1.10\left(\mathrm{~d}, \mathrm{~J}=9.6 \mathrm{~Hz}, 3 \mathrm{H}, \mathrm{CH}_{3}\right), 1.26(\mathrm{~d}, \mathrm{~J}=$ $\left.4.2 \mathrm{~Hz}, 3 \mathrm{H}, \mathrm{CH}_{3}\right), 1.42\left(\mathrm{~s}, 9 \mathrm{H}, \mathrm{CH}_{3}\right), 1.32-2.00(\mathrm{~m}, 26 \mathrm{H}$, cholyl), $2.35(\mathrm{~d}$, $\mathrm{J}=8.4 \mathrm{~Hz}, 1 \mathrm{H}, \mathrm{CH}), 2.22(\mathrm{~d}, \mathrm{~J}=9.6 \mathrm{~Hz}, 1 \mathrm{H}, \mathrm{CH}), 3.45$ (brs, $1 \mathrm{H}, \mathrm{NH})$, $3.68\left(\mathrm{dd}, \mathrm{J}=10.8,72.0 \mathrm{~Hz}, 2 \mathrm{H}, \mathrm{CH}_{2}\right), 3.86(\mathrm{~s}, 1 \mathrm{H}, \mathrm{CH}), 3.99(\mathrm{~s}, 1 \mathrm{H}, \mathrm{CH})$, $4.12(\mathrm{q}, 1 \mathrm{H}, \mathrm{J}=5.6 \mathrm{~Hz}, \mathrm{CH}), 4.90(\mathrm{~d}, 1 \mathrm{H}, \mathrm{J}=6.8 \mathrm{~Hz}, \mathrm{OH}), 4.97(\mathrm{brs}, 1 \mathrm{H}$, $\mathrm{CH}), 5.14\left(\mathrm{dd}, 2 \mathrm{H}, \mathrm{J}=9.6,30.8 \mathrm{~Hz}, \mathrm{CH}_{2}\right), 5.50$ (brs, $\left.1 \mathrm{H}, \mathrm{CH}\right), 6.49(\mathrm{~d}$, $1 \mathrm{H}, \mathrm{J}=7.2 \mathrm{~Hz}, \mathrm{NH}), 7.38\left(\mathrm{~s}, 5 \mathrm{H}, \mathrm{C}_{6} \mathrm{H}_{5}\right)$.

${ }^{13}$ CNMR: 175.7, 172.1, 172.1 171.1, 171.0, 171.0, 141.0, 128.8, 128.8, 127.5, 127.4, 82.1, 72.1, 71.9, 71.6, 69.0, 60.0, 51.9, 50.6, 50.0, 46.9, 45.7, $44.8,42.8,41.8,37.7,37.2,37.2,35.3,33.1,32.2,31.4,30.5,29.3,29.0$, $28.8,25.4,17.9,16.7,12.5,14.1,6.5$.

HRMS (FAB) for $\mathrm{C}_{49} \mathrm{H}_{75} \mathrm{~N}_{5} \mathrm{O}_{13}: \mathrm{m} / \mathrm{z}$ Found 941.5427, Calcd.941.5438. MS m/z $965(\mathrm{M}+\mathrm{Na}+2)^{+}, 960(\mathrm{M}+\mathrm{Na}-3)^{+}, 943(\mathrm{M}+2)^{+}$.

\section{Cholyl-[L-Thr-(D-Ala-BocGly) Ester] Amide (8a)}

Compound 7a was deprotected using a method similar to that described for $4 \mathrm{~b}$ to obtain $8 \mathrm{a}(277 \mathrm{mg}, 89 \%)$ as syrup.

${ }^{1} \mathrm{HNMR}\left(400 \mathrm{MHz}, \mathrm{CD}_{3} \mathrm{OD}\right) 0.70\left(\mathrm{~s}, 3 \mathrm{H}, \mathrm{CH}_{3}\right), 0.91\left(\mathrm{~s}, 3 \mathrm{H}, \mathrm{CH}_{3}\right)$, $1.04\left(\mathrm{~d}, \mathrm{~J}=5.8 \mathrm{~Hz}, 3 \mathrm{H}, \mathrm{CH}_{3}\right), 1.10\left(\mathrm{~d}, \mathrm{~J}=9.8 \mathrm{~Hz}, 3 \mathrm{H}, \mathrm{CH}_{3}\right), 1.24(\mathrm{~d}, \mathrm{~J}=$ $\left.5.9 \mathrm{~Hz}, 3 \mathrm{H}, \mathrm{CH}_{3}\right), 1.45\left(\mathrm{~s}, 9 \mathrm{H}, \mathrm{CH}_{3}\right), 1.32-2.00(\mathrm{~m}, 26 \mathrm{H}$, cholyl), 2.35 $(\mathrm{d}, \mathrm{J}=8.4 \mathrm{~Hz}, 1 \mathrm{H}, \mathrm{CH}), 2.22(\mathrm{~d}, \mathrm{~J}=9.6 \mathrm{~Hz}, 1 \mathrm{H}, \mathrm{CH}), 3.68(\mathrm{dd}, \mathrm{J}=12.8$, $\left.72.0 \mathrm{~Hz}, 2 \mathrm{H}, \mathrm{CH}_{2}\right), 3.86(\mathrm{~s}, 1 \mathrm{H}, \mathrm{CH}), 3.99(\mathrm{~s}, 1 \mathrm{H}, \mathrm{CH}), 4.12(\mathrm{q}, 1 \mathrm{H}, \mathrm{J}=$ 
$5.6 \mathrm{~Hz}, \mathrm{CH}), 4.97$ (brs, $1 \mathrm{H}, \mathrm{CH}), 5.14\left(\mathrm{dd}, 2 \mathrm{H}, \mathrm{J}=9.6,30.8 \mathrm{~Hz}, \mathrm{CH}_{2}\right)$, 5.40 (brs, $1 \mathrm{H}, \mathrm{CH}$ ).

${ }^{13}$ CNMR: 177.2, 174.8, 172.1 171.0, 157.9, 82.3, 71.9, 70.8, 70.7, 50.6, 50.0, 48.7, 44.8, 42.8, 41.8, 37.2, 37.2, 37.7, 35.3, 33.1, 32.2, 31.4, $30.5,29.3,29.0,28.8,28.7,28.7,25.4,17.9,16.7,14.1,12.5,6.5$.

HRMS (FAB) for $\mathrm{C}_{38} \mathrm{H}_{63} \mathrm{~N}_{3} \mathrm{NaO}_{11}: \mathrm{m} / \mathrm{z}$ Found 759.4567, Calcd.759.4563

MS: $\mathrm{m} / \mathrm{z} 777(\mathrm{M}+2 \mathrm{Na}-4)^{+}, 757(\mathrm{M}+\mathrm{Na}-2)^{+}$.

\section{Cholyl-[L-(OBzl)Thr-(D-Ala-Gly-Gly-Gly) Ester] Amide (8b)}

To a solution of $7 \mathrm{~b}(200 \mathrm{mg}, 0.24 \mathrm{mmol})$ in DCM (5 ml), TFA $(99 \%, 3 \mathrm{ml})$ was slowly added at ambient temperature. The mixture was stirred for 4 hours, condensed in a vacuum to remove the solvent and excess TFA. The residue was separated through silica gel column chromatography (ethyl acetate/methanol from 100:0 to 50:50) to obtain the pale white solid of $8 \mathrm{~b}\left(168 \mathrm{mg}, 94 \%\right.$; $\left.\mathrm{mp} 112-115^{\circ} \mathrm{C}\right)$.

${ }^{1} \mathrm{HNMR}\left(400 \mathrm{MHz}, \mathrm{CDCl}_{3}\right) 0.69$ (s, 3H, $\left.\mathrm{CH}_{3}\right), 0.90$ (s, 3H, $\mathrm{CH}_{3}$ ), $1.01\left(\mathrm{~d}, \mathrm{~J}=4.8 \mathrm{~Hz}, 3 \mathrm{H}, \mathrm{CH}_{3}\right), 1.11\left(\mathrm{~d}, \mathrm{~J}=9.3 \mathrm{~Hz}, 3 \mathrm{H}, \mathrm{CH}_{3}\right), 1.26(\mathrm{~d}, \mathrm{~J}$ $\left.=4.2 \mathrm{~Hz}, 3 \mathrm{H}, \mathrm{CH}_{3}\right), 1.32-2.00(\mathrm{~m}, 26 \mathrm{H}$, cholyl $), 2.35(\mathrm{~d}, \mathrm{~J}=8.4 \mathrm{~Hz}, 1 \mathrm{H}$, $\mathrm{CH}), 2.22(\mathrm{~d}, \mathrm{~J}=9.6 \mathrm{~Hz}, 1 \mathrm{H}, \mathrm{CH}), 3.45(\mathrm{brs}, 1 \mathrm{H}, \mathrm{NH}), 3.68(\mathrm{dd}, \mathrm{J}=10.8$, $\left.72.0 \mathrm{~Hz}, 2 \mathrm{H}, \mathrm{CH}_{2}\right), 3.86(\mathrm{~s}, 1 \mathrm{H}, \mathrm{CH}), 3.99(\mathrm{~s}, 1 \mathrm{H}, \mathrm{CH}), 4.12(\mathrm{q}, 1 \mathrm{H}, \mathrm{J}=$ $5.6 \mathrm{~Hz}, \mathrm{CH}), 4.90(\mathrm{~d}, 1 \mathrm{H}, \mathrm{J}=6.8 \mathrm{~Hz}, \mathrm{OH}), 4.97(\mathrm{brs}, 1 \mathrm{H}, \mathrm{CH}), 5.14(\mathrm{dd}$, $\left.2 \mathrm{H}, \mathrm{J}=9.6,30.8 \mathrm{~Hz}, \mathrm{CH}_{2}\right), 5.50$ (brs, $\left.1 \mathrm{H}, \mathrm{CH}\right), 6.49(\mathrm{~d}, 1 \mathrm{H}, \mathrm{J}=7.2 \mathrm{~Hz}$, $\mathrm{NH}), 7.38\left(\mathrm{~s}, 5 \mathrm{H}, \mathrm{C}_{6} \mathrm{H}_{5}\right)$.

${ }^{13}$ CNMR: $174.8,172.1,172.1171 .1,171.0,171.0,157.9,142.0,142.0$, 141.0, 136.7, 136.6, 128.9, 128.9, 128.8, 128.7, 127.8, 127.8, 127.9, 127.9, $127.4,127.3,127.3,126.7,126.5,82.1,73.0,72.1,71.9,71.2,69.0,59.7$, 51.9, 50.6, 50.0, 47.9, 46.9, 46.2, 44.8, 42.8, 41.8, 37.9, 37.7, 37.2, 37.2, $35.2,33.1,32.2,30.5,29.3,29.0,28.8,25.3,17.9,16.7,14.1,12.5,6.5$.

HRMS (FAB) for $\mathrm{C}_{44} \mathrm{H}_{67} \mathrm{~N}_{5} \mathrm{O}_{11}: \mathrm{m} / \mathrm{z}$ Found 841.4892, Calcd.841.4886. MS: $\mathrm{m} / \mathrm{z} 842(\mathrm{M}+1)^{+}$.

\section{Cholyl-[L-Thr-(D-Ala-Gly) Ester] Amide (9a)}

Compound 8a was deprotected using a method similar to that described for $\mathbf{8 b}$ to obtain syrup of $\mathbf{9 a}(205 \mathrm{mg}, 86 \%)$.

${ }^{1} \mathrm{HNMR}\left(400 \mathrm{MHz}, \mathrm{CD}_{3} \mathrm{OD}\right) 0.71\left(\mathrm{~s}, 3 \mathrm{H}, \mathrm{CH}_{3}\right), 0.91$ (s, 3H, $\left.\mathrm{CH}_{3}\right)$, $1.01\left(\mathrm{~d}, \mathrm{~J}=4.8 \mathrm{~Hz}, 3 \mathrm{H}, \mathrm{CH}_{3}\right), 1.11\left(\mathrm{~d}, \mathrm{~J}=9.7 \mathrm{~Hz}, 3 \mathrm{H}, \mathrm{CH}_{3}\right), 1.28(\mathrm{~d}, \mathrm{~J}=$ $\left.4.4 \mathrm{~Hz}, 3 \mathrm{H}, \mathrm{CH}_{3}\right), 1.32-2.00(\mathrm{~m}, 26 \mathrm{H}$, cholyl), $2.35(\mathrm{~d}, \mathrm{~J}=8.4 \mathrm{~Hz}, 1 \mathrm{H}$, $\mathrm{CH}), 2.22(\mathrm{~d}, \mathrm{~J}=9.6 \mathrm{~Hz}, 1 \mathrm{H}, \mathrm{CH}), 3.45$ (brs, $1 \mathrm{H}, \mathrm{NH}), 3.68(\mathrm{dd}, \mathrm{J}=10.8$, $\left.72.0 \mathrm{~Hz}, 2 \mathrm{H}, \mathrm{CH}_{2}\right), 3.86(\mathrm{~s}, 1 \mathrm{H}, \mathrm{CH}), 3.99(\mathrm{~s}, 1 \mathrm{H}, \mathrm{CH}), 4.12(\mathrm{q}, 1 \mathrm{H}, \mathrm{J}=$ $5.6 \mathrm{~Hz}, \mathrm{CH}), 4.90(\mathrm{~d}, 1 \mathrm{H}, \mathrm{J}=6.8 \mathrm{~Hz}, \mathrm{OH}), 4.97$ (brs, $1 \mathrm{H}, \mathrm{CH}), 5.14(\mathrm{dd}$, $\left.2 \mathrm{H}, \mathrm{J}=9.6,30.8 \mathrm{~Hz}, \mathrm{CH}_{2}\right), 5.50$ (brs, $\left.1 \mathrm{H}, \mathrm{CH}\right), 6.49(\mathrm{~d}, 1 \mathrm{H}, \mathrm{J}=7.2 \mathrm{~Hz}$, $\mathrm{NH}), 7.38\left(\mathrm{~s}, 5 \mathrm{H}, \mathrm{C}_{6} \mathrm{H}_{5}\right)$.

${ }^{13}$ CNMR: 177.2, 174.8, 172.1 171.0, 157.9, 82.3, 71.9, 70.8, 70.7, 50.6, 50.0, 48.7, 44.8, 42.8, 41.8, 37.2, 37.2, 37.7, 35.3, 33.1, 32.2, 31.4, $30.5,29.3,29.0,28.8,28.7,28.7,25.4,17.9,16.7,14.1,12.5,6.5$.

HRMS (FAB) for $\mathrm{C}_{33} \mathrm{H}_{55} \mathrm{~N}_{3} \mathrm{O}_{9}: \mathrm{m} / \mathrm{z}$ Found 637.3980, Calcd.637.3977. MS: $\mathrm{m} / \mathrm{z} 638(\mathrm{M}+1)^{+}$.

\section{Cholyl-[L-Thr-(D-Ala-Gly-Gly-Gly) Ester] Amide (9b)}

Compound $\mathbf{8 b}$ was deprotected using a method similar to that described for $\mathbf{4}$ to give a solid of $\mathbf{9 b}\left(164 \mathrm{mg}, 92 \%\right.$; mp $\left.110-114^{\circ} \mathrm{C}\right)$.

${ }^{1} \mathrm{HNMR}\left(400 \mathrm{MHz}, \mathrm{CD}_{3} \mathrm{OD}\right) 0.70\left(\mathrm{~s}, 3 \mathrm{H}, \mathrm{CH}_{3}\right), 0.91\left(\mathrm{~s}, 3 \mathrm{H}, \mathrm{CH}_{3}\right)$, $1.04\left(\mathrm{~d}, \mathrm{~J}=5.8 \mathrm{~Hz}, 3 \mathrm{H}, \mathrm{CH}_{3}\right), 1.11\left(\mathrm{~d}, \mathrm{~J}=9.7 \mathrm{~Hz}, 3 \mathrm{H}, \mathrm{CH}_{3}\right), 1.24(\mathrm{~d}, \mathrm{~J}=$ $\left.5.9 \mathrm{~Hz}, 3 \mathrm{H}, \mathrm{CH}_{3}\right), 1.32-2.00(\mathrm{~m}, 30 \mathrm{H}$, cholyl $\mathrm{CH}), 2.35(\mathrm{~d}, \mathrm{~J}=8.4 \mathrm{~Hz}, 1 \mathrm{H}$, $\mathrm{CH}), 2.22(\mathrm{~d}, \mathrm{~J}=9.6 \mathrm{~Hz}, 1 \mathrm{H}, \mathrm{CH}), 3.68\left(\mathrm{dd}, \mathrm{J}=12.8,72.0 \mathrm{~Hz}, 2 \mathrm{H}, \mathrm{CH}_{2}\right)$, $3.86(\mathrm{~s}, 1 \mathrm{H}, \mathrm{CH}), 3.99(\mathrm{~s}, 1 \mathrm{H}, \mathrm{CH}), 4.12(\mathrm{q}, 1 \mathrm{H}, \mathrm{J}=5.6 \mathrm{~Hz}, \mathrm{CH}), 4.97$ (brs, $1 \mathrm{H}, \mathrm{CH}$ ), $5.14\left(\mathrm{dd}, 2 \mathrm{H}, \mathrm{J}=9.6,30.8 \mathrm{~Hz}, \mathrm{CH}_{2}\right), 5.40$ (brs, $1 \mathrm{H}, \mathrm{CH}$ ), $6.49(\mathrm{~d}, 1 \mathrm{H}, \mathrm{J}=7.2 \mathrm{~Hz}, \mathrm{NH})$.

${ }^{13}$ CNMR: $177.3,174.8,172.2171 .1,170.0,82.3,71.9,70.8,69.0$, $61.8,51.9,50.6,50.0,46.9,46.3,45.7,44.8,42.8,41.8,37.7,37.2,35.3$, $33.1,32.2,31.4,30.5,29.3,29.0,28.8,25.4,17.9,16.7,14.1,12.5,6.5$.

HRMS (FAB) for $\mathrm{C}_{37} \mathrm{H}_{61} \mathrm{~N}_{5} \mathrm{O}_{11}: \mathrm{m} / \mathrm{z}$ Found 751.4491, Calcd.751, 4462. MS: m/z $752(\mathrm{M}+1)^{+}$.

\section{Cell culture}

Cell seed were kept in freeze 95\% culture medium and 5\% DMSO. It was sub-cultured in removing medium, rinsing with $0.25 \%$ trypsin, $0.03 \%$ EDTA solution, removing the solution and adding an additional 1 to $2 \mathrm{ml}$ of trypsin-EDTA solution in each flask. CaCo-2 cells were grown in $75 \mathrm{~cm}^{2}$ plastic cell culture flasks containing $2.5 \mathrm{ml}$ highglucose $(4.5 \mathrm{mg} / \mathrm{l})$ DMEM with 20\% FBS, 1\% NEAAs, penicillin (100 $\mathrm{U} / \mathrm{ml})$ and streptomycin $(100 \mu \mathrm{g} / \mathrm{ml})$. The flasks were placed in a humidified, $5 \% \mathrm{CO}_{2}-95 \%$ air incubator at $37^{\circ} \mathrm{C}$ until the cells reached approximately $80 \%$ confluence. The cells were trypsiniaed and plated at a density of $64,000 \mathrm{cdlls} / \mathrm{cm}^{2}$ on Costar Transwell ${ }^{\mathrm{TM}}$ polycarbonate membranes which were previously coated with rat tail collagen. The cell culture medium, $1.5 \mathrm{ml}$ apical side and $2.5 \mathrm{ml}$ basolateral side, was replaced every other day for the first week and daily thereafter. Experiments were performed on 33 to 32 days after seeding, if transfer of mannitol reached values of $0.5 \% / \mathrm{h}$, the results were not included in the analysis due to the possibility of membrane leakage.

\section{Trans-epithelial transport and degradation studies}

Cell monolayers were washed twice with modified Hanks' balanced salt solution (HBSS) and allowed to equilibrate for $20 \mathrm{~min}$ at $37^{\circ} \mathrm{C}$. The transepithelial transport of cholic acid ester conjugates were determined in $\mathrm{CaCo}-2$ cell line at $37^{\circ} \mathrm{C}$, both in the apical to basal and basal to apical. Samples were added to apical side in $1.5 \mathrm{ml} \mathrm{HBSS}$ and methanol and $2.5 \mathrm{ml}$ same solvent to basolateral side, and vise verse. Taken samples from both side chambers in interval designed time.

\section{Analysis}

Analysis were performed on Beckman Coulter Gold 126 High Proficiency Liquid Chromatography (HPLC), 166 Programmable UV/VIS detector, the column is C-18 reversed-phase $(5 \mu \mathrm{m} \times 10 \mathrm{~cm}$ long), the mobile phase consisted of methanol and water 75:25, 70:30 to $40: 60(\mathrm{v} / \mathrm{v})$ respectively, at a flow rate of $1 \mathrm{ml} / \mathrm{min}$. Wavelength of record was selected at $254 \mathrm{~nm}$, because that most of the compounds have maximum absorption at this wavelength.

\section{Results and Discussion}

As indicated in Schemes 2 and 3, a threonine moiety was introduced at the $\mathrm{C} 24$ position of cholic acid to produce an ester linker between cholic acid and the peptide unit. The selection of a threonine moiety presents several advantages over other amino acid linkers. First, the threonine linker possesses an ionizing group, the carboxyl group at the $\mathrm{C} 26$ position, which provides a negative charge adjacent to the C24 position to meet bile acid transport requirement. The threonine linker also provides one hydroxyl group (at C27 position) that can be used to construct an ester bond. The methyl of threonine provides 
some hydrophobicity that also infects binding process. Furthermore, as indicated in our experiment, the hydroxyl group on the threonine moiety is more reactive than three other hydroxyl groups on steroid ring making it possible selectively to construct the ester bond at C27 position under less stringent conditions.

It is common that the coupling reagent 1,3-dicycloheylcarbodiimide (DCC) has been widely used to form amides in peptide synthesis. This procedure usually requires the conversion of the carboxylic group to an active ester as the first step $[18,19]$. To simplify the reaction procedure, we used a catalytic amount of N-hydroxysuccinimide to form the amide. Our result indicates that a small portion of $\mathrm{N}$ hydroxysuccinimide (10\%) is sufficient to make an amide condensation both in tetrahydrofuran (THF) and in dichloromethane (DCM). The synthesis procedure was thus shortened and the normal steps of making and separating the active ester were avoided. The reaction produced a relatively high yield of amide with only minor amounts of byproducts.

To synthesize potentially useful cholic acid-peptide conjugates, it is important to selectively introduce the ester bond at the $\mathrm{C} 27$ position (Scheme 1) between threonine and peptide. Three other hydroxyl groups on the steroid ring of cholic acid at C3, C7, and C12 also have the potential of forming ester bonds with peptide unit resulting in an unwanted mixture of different peptide esters. To avoid side reactions and to increase the regio-selectivity of esterification, ethyl acetate was used as the solvent for DCC esterification reaction in the presence of a small amount of 4-dimethylaminopyridine (DMP) (5\%) or triethylamine (TEA) (10\%) as catalyst [20,21]. Among several solvents examined in our experiments, ethyl acetate was found to be the most suitable because of the higher selectivity and higher yield than other solvents including dichloromethane, tetrahydrofuran and acetonitrile. Without any additional protection steps, the reaction selectively occurred at the C27 position with high yields (3: $82 \%$, Scheme 1). The selectivity of the reaction was confirmed by ${ }^{1} \mathrm{H}$ NMR data.

Fluoride ion (F-) was used to cleave 9-Fluorenylmethoxycarbonyl (Fmoc) (Scheme $3 b$ ) from the amino groups in a mixture of $\mathrm{N}$, $\mathrm{N}$-dimethylformamide (DMF) and THF at ambient temperature. In peptide synthesis, Fmoc has been commonly utilized to protect amino groups with piperidine as the de-protecting reagent. It is efficient and convenient, particularly in solid phase synthesis [22,23]. However, in our procedure involving solution phase synthesis, we found it difficult to remove the residue of excess piperidine from the reaction mixture [24] and thus to separate the de-protected products. In addition,

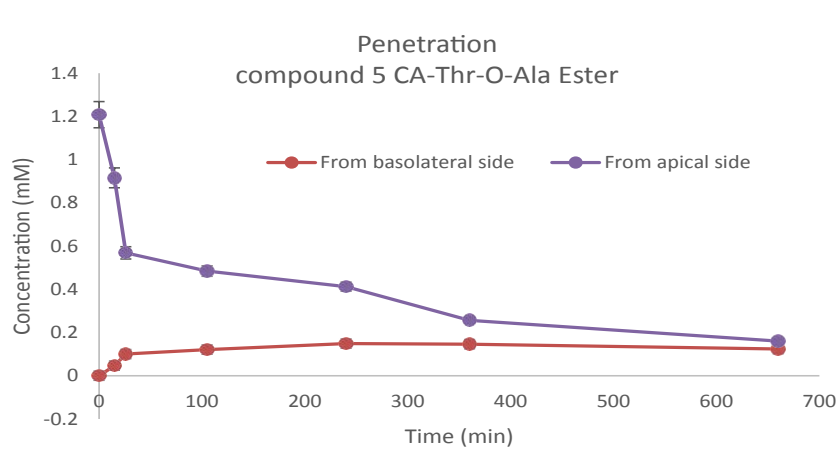

Penetration

9a CA-Thr-O-Ala-Gly conjugate Ester

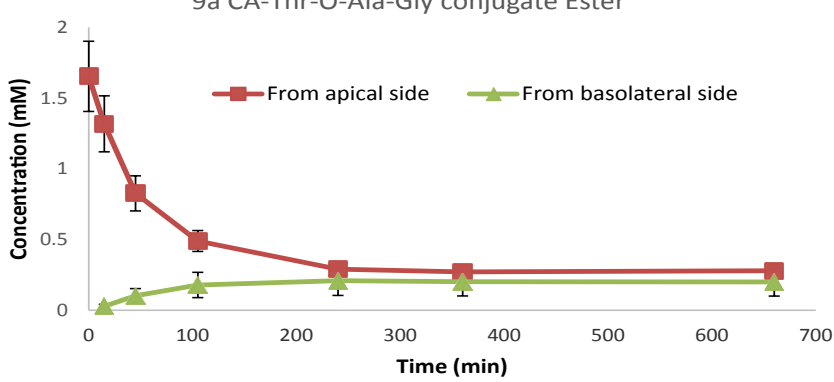

Penetration

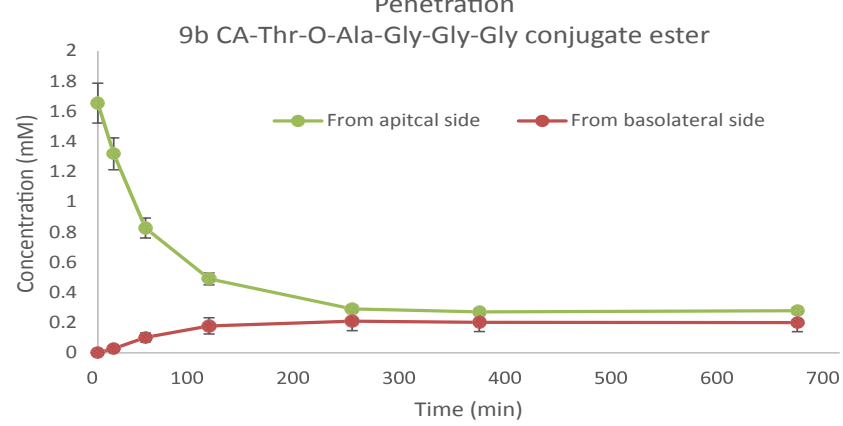

Figure 2: Penetration of 9a CA-Thr-O-Ala-Gly conjugate ester. 
intramolecular aminolysis and other side reactions occurred, similar to those reported in the literature $[25,26]$. To solve this problem, potassium fluoride $(\mathrm{KF})$ was selected as the cleavage reagent $[27,28]$. In the mixture of DMF and THF containing KF, the de-protection was completed quantitatively in a few hours at room temperature in the presence of TEA. The resulting product was used directly without any additional separation steps. Aminolysis at the ester bond between threonine and the amino acid chains was not detected under this procedure.

Cell membrane transporting was carried out on CaCo-2 cell line model. The initial results demonstrated that the penetrations were including both ways that are diffusion and active transporting. The results informed in Figures 1 and 2, first, all of the substrates passed through the membrane in same time, about 250 minutes, and then equilibrated. Second, the template of the conjugate, compound 3 CA-Thr (Figure 1) has almost same concentration on both sides, apical and basolateral, and the substrate recovery of the two sides are equality, which means there were no substrate losing nor gaining, or no degradation because without ester bond yet. Third, all three conjugates, compounds 5, 9a and $9 \mathrm{~b}$ were degraded about $87 \%$ after equilibrium from the recovery of the substrate on both sides, indicated a further study on precise detection of degradation would be done.

\section{Conclusion}

Cell culture experiment showed the efficiencies of transporting of the conjugates and the dissociation of the conjugates, suggesting that the cholic acid conjugates linked by degradable ester bond can be used as bigger molecule drugs delivering template. Further study would be designed by using more different linkers that would be also biodegradable bonds, such as thioester and so forth. Further synthetic method of longer cholic acid and peptides conjugates via ester bond linker need to be addressed, particularly solid phase approaches.

\section{Acknowledgement}

This publication was made possible by Grant Number GM 53969 from NIH. Its contents are solely the responsibility of the authors and do not necessarily represents the official views of the NIH

\section{References}

1. Kessler H, Haupt A, Schudok M, Ziegler K, Frimmer M (1988) Peptide conformations--49(1): synthesis and structure-activity relationships of side chain modified peptides of cyclo(-D-Pro-Phe-Thr-Lys-Trp-Phe.). Int J Pept Protein Res 32: 183-193.

2. Li H, Jiang X, Howell SB, Goodman M (2000) Synthesis, conformational analysis and bioactivity of Lan-7, a lanthionine analog of TT-232. J Pept Sc 6: 26-35.

3. Li H, Wang LX (2003) Cholic acid as template for multivalent peptide assembly Org Biomol Chem 1: 3507-3513.

4. Audus KL, Raub TJ (1993) Biological barriers to protein delivery. Plenum, New York. p. 495.

5. Mills CO, Elias E (1992) Biliary excretion of chenodeoxycholyllysylrhodamine in Wistar rats: A possible role of a bile acid as a carrier for drugs. Biochim Biophys Acta 1126: 35-40.

6. Artursson P, Karlsson JO, Ocklind GO, Schipper NI (1996) Studying transport processes in absorptive epithelia. Epithelial cell culture: A practical approach.

7. Swaan PW, Hillgren KM, Szoka FC, Oie S (1997) Enhanced transepithelial

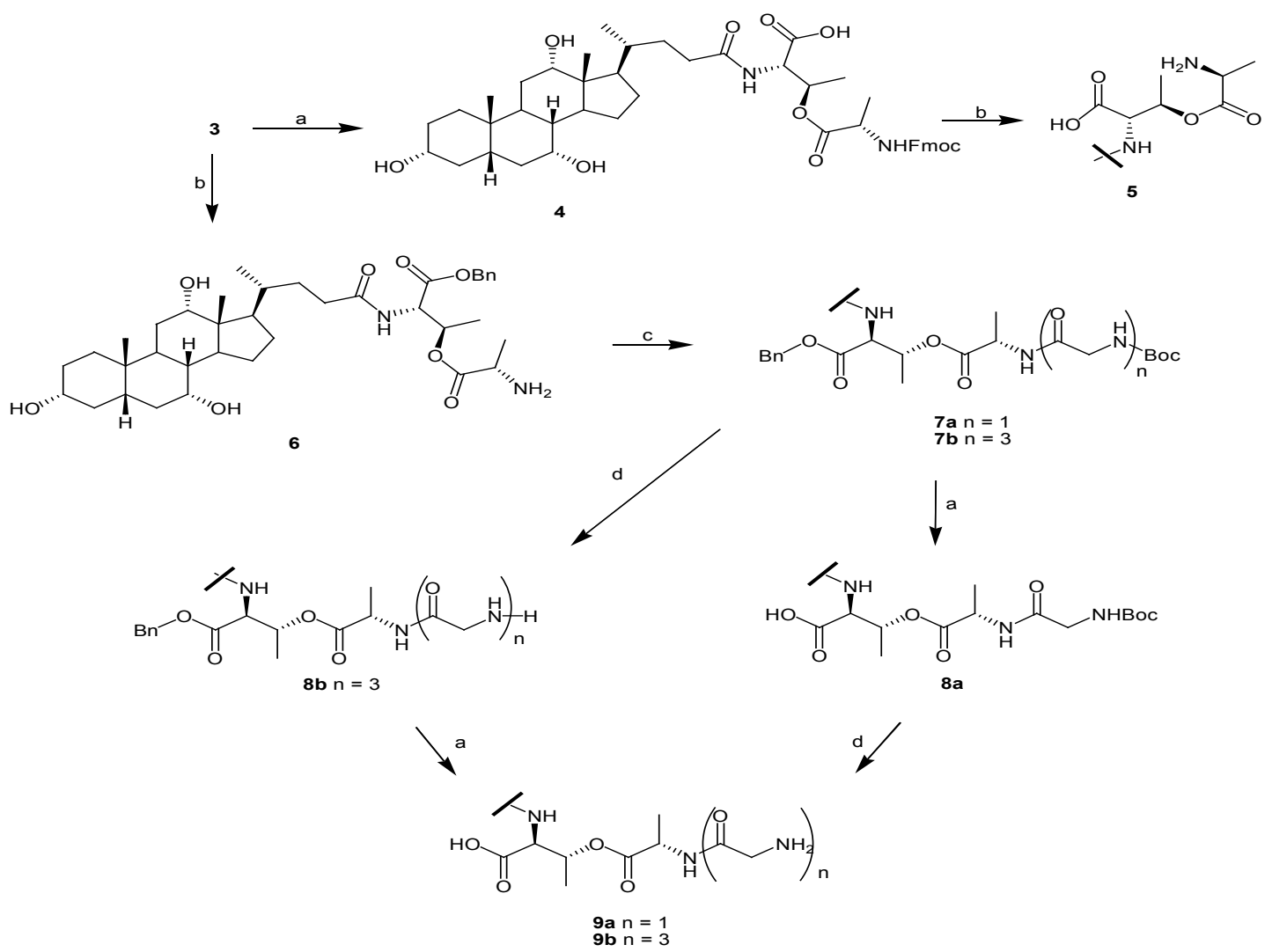

Scheme 3: Reagents and condition: (a) $\mathrm{H}_{2}, 10 \% \mathrm{Pd} / \mathrm{C}$, methanol, room temperature; (b) KF, TEA, DMF (or piperidine), DCM r.t.; (c) DCC, peptides or protected amino acids, DMAP (or TEA), DMF/THF; (d) $55 \%$ trifluoroacetic acid (TFA) in DCM, r. t.. 
Citation: Li H, Song H, Oie S, Lu RD (2017) Synthesis of Cholic Acid-Peptide Conjugates With A Negatively Charged Ester Linkage for Oral Delivery. Med Chem (Los Angeles) 7: 769-776. doi: 10.4172/2161-0444.1000428

transport of peptides by conjugation to cholic acid. Bioconjug Chem 8: 520-525.

8. Ho NF (1987) Utilizing bile acid carrier mechanisms to enhance liver and smal intestine absorption. Ann NY Acad Sci 507: 315-329.

9. Kramer W, Wess G, Neckermann G, Schubert G, Fink J, et al. (1994) Intestinal absorption of peptides by coupling to bile acids. J Biol Chem 269: 10621-10627.

10. Kim DC, Harrison AW, Ruwart MJ, Wilkinson KF, Fisher JF, et al. (1993) Evaluation of the bile acid transporter in enhancing intestinal permeability to renin-inhibitory peptides. J Drug Target 1: 347-359.

11. Swaan PW, Szoka FC, Oie S (1996) Use of the intestinal and hepatic bile acid transporters for drug delivery. Adv Drug Deliv Rev 20: 59-82.

12. Schramm U, Dietrich A, Schneider S, Buscher HP, Gerok W, et al. (1991) Fluorescent derivatives of bile salts. II. Suitability of NBD-amino derivatives of bile salts for the study of biological transport. J Lipid Res 32: 1769-1779.

13. Lack L, Walker JT, Singletary GD (1970) lleal bile salt transport: In vivo studies of effect of substrate ionization on activity. Am J Physiol 219: 487-490.

14. Hardison WG, Heasley VL, Shellhamer DF (1991) Specificity of the hepatocyte $\mathrm{Na}(+)$-dependent taurocholate transporter: influence of side chain length and charge. Hepatology 13: 68-72.

15. Kågedahl M, Swaan PW, Redemann CT, Tang M, Craik CS, et al. (1997) Use of the intestinal bile acid transporter for the uptake of cholic acid conjugates with HIV-1 protease inhibitory activity. Pharm Res 14: 176-180.

16. Anwer MS, O'Maille ER, Hofmann AF, DiPietro RA, Michelotti E (1985) Influence of side-chain charge on hepatic transport of bile acids and bile acid analogues. Am J Physiol 249: G479-488.

17. Swaan PW, Szoka FC, Oie S (1997) Molecular modeling of the intestinal bile acid carrier: A comparative molecular field analysis study. J Comput Aided Mol Des 11: $581-588$

18. Jones J (1992) Amino acid and peptides synthesis. Oxford University.

19. Idziak I, Gravel D, Zhu XX (1999) Polymer-catalyzed aminolysis of covalently imprinted cholic acid derivative. Tetrahedron Lett 40: 9167-9170.

20. Hassner A, Alexanian $V(1978)$ Direct room temperature esterification of carboxylic acids. Tetrahedron Lett 19: 4475-4478.

21. Boden EP, Keck GE (1985) Proton-transfer steps in Steglich esterification: A very practical new method for macrolactonization. J Org Chem 50: 2394-2395.

22. Carpino LA, Chao HG, Beyermann M, Bienert M (1991) [(9-Fluorenylmethyl) oxy] carbonyl (Fmoc) amino acid chlorides in solid-phase peptide synthesis. $J$
Org Chem 56: 2635-2642.

23. Carpino LA (1987) The 9-fluorenylmethyloxycarbonyl family of base-sensitive amino-protecting groups. Acc Chem Res 20: 401-407.

24. Carpino LA, Cohen BJ, Stephens KE, Sadat-Aalaee SY, Tien JH, et al. (1986) (Fluoren-9-ylmethoxy) carbonyl (Fmoc) amino acid chlorides: Synthesis, characterization, and application to the rapid synthesis of short peptide segments. J Org Chem 51: 3732-3734.

25. Pedroso E, Grandas A, De las Heras X, Eritja R, Giralt E (1986) Diketopiperazine formation in solid phase peptide synthesis using p-alkoxybenzyl ester resins and Fmoc-amino acids. Tetrahedron Lett 27: 743-746.

26. Ueki M, Amemiya M (1987) Removal of 9-fluorenylmethyloxycarbonyl (Fmoc) group with tetrabutylammonium fluoride. Tetrahedron Lett 28: 6617-6620.

27. Li WR, Chou HH (2000) A facile synthesis of amides from 9-fluorenylmethyl carbamates and acid derivatives. Synthesis 1: 84-90.

28. Leggio A, Liguori A, Napoli A, Siciliano C, Sindona G (2000) New strategies for an efficient removal of the 9-Fluorenylmethoxycarbonyl (Fmoc) protecting group in the peptide synthesis. Eur J Org Chem 2000: 573-574. 